\title{
Analisis Pendapatan dan Kesejahteraan Keluarga Petani Sawah Di Kelurahan Salomallori Kecematan Dua Pitue Kabupaten Sidrap
}

\author{
Analysis of Income and Welfare of Rice Farmer Families In Salomallori Villange, Dua \\ Pitue Subdistrict, Sidrap Regency \\ Ismayanti $^{1^{*}}$, Nurhapsa ${ }^{1}$, A. Erna Sriwahyuningsih ${ }^{1}$ \\ "Email: ismayantiismayanti800@gmail.com \\ ${ }^{1}$ Program Studi Agribisnis, Fak. Pertanian, Peternakan dan Perikanan, Universitas Muhammadiyah Parepare \\ Diterima: 01 Mei 2021 / Disetujui: 02 Agustus 2021
}

\begin{abstract}
ABSTRAK
Kelurahan Salomallori merupakan Kelurahan yang mata pencahariannya yang paling banyak adalah sebagai petani, dimana di Kelurahan ini masih kental dengan tradisinya. Penelitian ini bertujuan untuk menentukn tingkat pendapatan dan kesejahteraan petani. Jenis penelitian yang digunakan adalah kuantitatif dan kualitatif, Teknik pengumpulan datanya adalah observasi, wawancara dan Quisioner. Data yang digunakan adalah data sekunder dan data primer. Penelitian ini terdapat 25 responden. Berdasarkan hasil penelitian menunjukkan total pendapatan petani padi di Kelurahan Salomallori adalah Rp.673.229.650/panen. Nilai Return Cost Ratio (R/C-ratio) adalah 5 yang menunjukkan bahwa usaha tani padi layak untuk di usahatanikan karena R/C Ratio yang di dapat 5 sama dengan 1 (R/C Ratio > 1). Tingkat kesejahteraan masih tergolong cukup rendah.
\end{abstract}

Kata Kunci: Pendapatan, Kesejahteraan, Usaha Tani, Petani Padi

\begin{abstract}
Salomallori village is a village with the most livelihoods being farmers, where in this Salomallori village is still thick with its traditions. This study aims to determine the level of income and welfare of farmers. The type of research used is quantitative and qualitative. The data collection techniques are observation, interview and questionnaire. The data used are secondary data and primary data. This study consisted of 25 respondents. Based on the research results, the total income of farmers in Salomallori village is $R p$. 673.229/harvest. The value of return cost ratio $(R / C$-ratio) is 5 which indicates that rice farming is feasible to be farmed because the $R / C$ ratio obtained is 5 equal to 1 $(R / c$ Ratio > 1). The level of welfare is still quite low.
\end{abstract}

Keywords: Income, Welfare, Farming, Rice Farmers

This work is licensed under Creative Commons Attribution License 4.0 CC-BY International license

\section{A. PENDAHULUAN}

Sektor pertanian merupakan sektor yang berpengaruh dalam pertumbuhan ekonomi nasional. Peranan sektor pertanian dalam pembagunan ekonomi yaitu sebagai sumber pendapatan, dan pembuka kesempatan kerja, pengentasan kemiskinan, dan peningkatan ketahanan pangan nasional.
Pembagunan pertanian suatu daerah tidak hanya bertujuan untuk meningkatkan produksi, namun juga mengarah pada peningkatan pendapatan masyarakat, perluasaan lapangan kerja, peningkatan taraf hidup petani serta peningkatan kesejahteraan (Soekartawi, 2003). 
Padi (Oryza ativa L) merupakan tanaman pangan yang sangat penting dan dipandang sebagai produk kunci bagi kestabilan perekonomian dan politik. Indonesia saat ini menghadapi masalah pangan akibat peningkatan jumlah penduduk yang yang diikuti oleh banyaknya sawah subur di Pulau Jawa yang beralih fungsi menjadi kawasan industri dan permukiman (Purnamaningsih, 2006).

Sidrap merupakan salah satu kontributor utama produksi beras, kontribusi mencapai 18 atau $20 \%$ salah satu sentral penghasil beras di Sulawesi Selatan. hal ini di dukung oleh jaringan irigasi teknis yang mampu mengairi sawah sepanjang tahun.

Permasalahan yang dihadapi di Kelurahan Salomallori yaitu permasalahan mengenai cuaca dimana setiap melakukan pemanenan pasti curah hujan semakin tinggi yang membuat padi sawah harus terendam air proses pemanenan terhambat dan hama tikus yang membuat produksi menurun dimana kedua permasalahan tersebuat membuat pendapatan petani berkurang karena produksi yang dihasilkan semakin kecil apabila pendapatan petani menurun bisa memberikan dampak terhadap tingkat kesejahteraan petani karena tingkat kesejahteraan petani bisa di lihat dari pendapatan petani itu sendiri apakah pendapatannya besar atau kecil.

\section{B. METODE PENELITIAN}

\section{Tempat dan Waktu}

Penelitian ini dilaksanakan selama 1 bulan mulai September sampai Oktober 2020 bertempat di Kelurahan Salomallori Kecematan Dua Pitue Kabupaten Sidrap.

\section{Populasi dan Sampel}

Pengambilan sampel dilakukan di Kelurahan Salomallori Kecematan Dua Pitue Kabupaten Sidrap, metode sampel yang digunakan yaitu simple random sampling, populasinya yaitu 251. Arikunto (2002), menyatakan bahwa jika jumlah populasi <100 maka jumlah sampel sama dengan jumlah populasi, jika jumlah populasi >100 maka sampel dapat diambil sebanyak 10-15 \%, sampel diambil sebanyak 25.

\section{Teknik Pengumpulan Data}

Teknik pengumpulan data yang digunakan sebagai berikut:

a. Observasi merupakan teknik pengumpulan data yang digunakan dengan mengambil secara langsung kegiatan oleh objek peneliti.

b. Wawancara merupakan teknik pengumpulan data yang langsung dalam bentuk tanya jawab dengan responden.

c. Quisioner merupakan pertayaan tertulis dengan diajukan kepada responden dalam menggunakan 
quisioner, maka peneliti akan banyak mendapatkan data secara factual.

\section{Analisis Data}

Adapun metode yang digunakan dalam analisis usaha tani padi adalah sebagai berikut:

a. Biaya Total

Biaya total adalah penjumlahan dari biaya tetap total (total fixed cost) dengan biaya tidak tetap total (total variable cost) dan dapat ditulis dengan rumus (Soekartawi 1995):

$$
\mathrm{TC}=\mathrm{FC}+\mathrm{VC}
$$

Keterangan:

$\mathrm{TC}=$ Total Cost (Biaya total $)$

$\mathrm{FC}=$ Fixed cost $($ Biaya tetap)

$\mathrm{VC}=$ Variable cost $($ Biay variabel $)$

b. Penerimaan

Penerimaan usaha tani adalah perkalian antara produksi yang diperoleh dengan harga jual produknya, dan dapat ditulis (Soekartawi 1995) :

$$
\mathrm{TR}=\mathrm{Q} \cdot \mathrm{P}
$$

Keterangan:

$\mathrm{TR}=$ Total Revenue (Total penerimaan)

$\mathrm{Q}=$ Produksi yang diperoleh dalam suatu usaha tani

$\mathrm{P}=$ Harga $\mathrm{Y}$

c. Pendapatan Usaha Tani

Untuk menghitung pendapatan dari usaha tani padi sawah digunakan rumus (Rahim dan Hastuti, 2008), yaitu:

$$
\Pi=\mathrm{TR}-\mathrm{TC}
$$

Keterangan:

$\pi=$ Pendapatan usaha tani

$\mathrm{TR}=$ Total penerimaan (total revenue)

$\mathrm{TC}=$ Total biaya $($ total cost $)$

\section{HASIL DAN PEMBAHASAN}

\section{Analisis Biaya Usaha Tani}

Biaya usaha tani yaitu biaya yang dikeluarkan seorang petani selama proses produksi. Besarnya biaya yang harus dikeluarkan untuk memproduksi satu komoditi ditentukan dari besarnya harga pokok yang akan dihasilkan selama proses usaha tani berlangsung, dimana biaya tersebut dibagi menjadi dua yaitu biaya variabel dan biaya tetap.

\section{a. Biaya Variabel}

Biaya Variabel yaitu biaya yang berubah-ubah yang besar kecilnya sangat tergantung pada biaya skala produksi dan habis dalam satu masa proses produksi.

Tabel 1. Total Biaya Varibel Yang Digunakan Oleh Responden Usaha Tani Padi

\begin{tabular}{lc}
\hline \multicolumn{1}{c}{ Biaya Variabel } & Nilai Biaya \\
\hline a. Bibit & 7.361 .600 \\
b. Pupuk & 43.947 .000 \\
c. Racun & 24.750 .000 \\
d. Penanaman & 5.800 .000 \\
e. Pemupukan & 6.975 .000 \\
f. Sewa mesin panen & 28.530 .000 \\
g. Pengankutan & 17.802 .000 \\
\hline Total Biaya Variabel & $\mathbf{1 3 5 . 1 6 5 . 6 0 0}$ \\
\hline Sumber. Data diolah 2020 & \\
Tabel di atas menunjukkan bahwa & oleh 25 \\
biaya variabel yang digunakan & \\
responden yaitu 7 biaya dimana biaya bibit \\
yang dikeluarkan sebesar Rp. 7.361.600 per \\
panen, biaya pupuk sebesar Rp.43.947.000 \\
per panen, biaya racun sebesar
\end{tabular}


Rp.24.750.000 per panen, biaya penanaman sebesar Rp. 5.800.000 per panen, pemupukan sebesar Rp. 6.975 .000 per panen, biaya sewa mesin panen sebesar Rp. 28.530.000 per panen dan biaya pengankutan sebesar Rp. 17.802.000 per panen, sehingga biaya yang dikeluarkan responden yaitu Rp. 135.165.600

\section{b. Biaya Tetap}

Biaya tetap yaitu biaya yang relatif tetap jumlahnya dan terus dikeluarkan walaupun produksi yang diperoleh banyak atau sedikit.

Tabel 2. Total Biaya Varibel Yang Digunakan Oleh Responden Usaha Tani Padi

\begin{tabular}{lc}
\hline \multicolumn{1}{c}{ Biaya Tetap } & Nilai Biaya \\
\hline a. Pajak & 3.410 .750 \\
b. Traktor & 26.850 .000 \\
\hline Total Biaya Tetap & $\mathbf{3 0 . 2 6 0 . 7 5 0}$ \\
\hline Sumber. Data diolah 2020 &
\end{tabular}

Tabel diatas menunjukkan bahwa biaya tetap yang digunakan oleh 25 responden yaitu biaya pajak dan biaya traktor, biaya pajak yang dikeluarkan oleh responden sebesar Rp. 3.410.750 per panen dan biaya traktor sebesar Rp.26.850.000 per panen, sehingga biaya tetap yang dikeluarkan oleh petani sebesar Rp30.260.750 per panen.

\section{Analisis Biaya, Penerimaan dan Pendapatan}

\section{a. Analisis Biaya}

Biaya yaitu sesuatu yang dikeluarkan pada saat usaha tani,ada dua macam biaya yaitu biaya tetap dan biaya variabel. Untuk mengetahui biaya responden dalam usaha tani padi dapat di analisis dengan rumus biaya yaitu:

Total Biaya Tetap $\quad=$ Rp.30.260.750

Total Biaya Variabel = Rp.135.165.600

Rumus

$$
\begin{aligned}
\mathrm{TC} & =\mathrm{FC}+\mathrm{VC} \\
& =\mathrm{Rp} \cdot 30 \cdot 260.750+\mathrm{Rp} \cdot 135 \cdot 165.600
\end{aligned}
$$

$\mathrm{TC}=\mathrm{Rp} \cdot 165.426 .350$

Berdasarkan analisis tersebut dapat diketahui biaya usaha tani yang dikeluarkan oleh 25 responden Di Kelurahan Salomallori Kecematan Dua Pitue Kabupaten Sidrap yaitu sebanyak Rp.165.426.350 per-panen. Rata-rata biaya usaha tani yang dikeluarkan Rp. 6.617.054. Hal ini sejalan dengan penelitian Namri (2017) dengan penelitian Di Kelurahan Watang Suppa Kecematan Suppa Kabupaten Pinrang dengan biaya yang dikeluarkan sebesar Rp. 47.845.236.

\section{b. Analisis Penerimaan}

Penerimaan diperoleh dari produksi yang dihasilkan akan dikalikaan dengan harga produksi, untuk mengetahui penerimaan responden dalam usaha tani padi dapat dianalisis dengan rumus penerimaan yaitu:

Jumlah Produksi $=174.720 \mathrm{Kg}$

Harga $\quad=$ Rp. 4.800 
Rumus

$\mathrm{TR}=\mathrm{Q} . \mathrm{P}$

$=(\mathrm{Rp} .174 .720 \mathrm{Kg}) \cdot(\mathrm{Rp} .4 .800)$

$\mathrm{TR}=\operatorname{Rp} .838 .656 .000$

Berdasarkan analisis tersebut dapat diketahui penerimaan usaha tani yang dikeluarkan oleh 25 responden Di Kelurahan Salomallori Kecematan Dua Pitue Kabupaten Sidrap yaitu sebanyak Rp. 838.656.000 per-panen. Rata-rata penerimaan usaha tani yang dikeluarkan Rp.33.546.240. Hal ini sejalan dengan penelitian Namri (2017) dengan penelitian Di Kelurahan Watang Suppa Kecematan Suppa Kabupaten Pinrang dengan penerimaan yang dihasilkan sebesar Rp.99.825.000.

\section{Analisis Pendapatan}

Pendapatan usaha tani padi sawah diperoleh dengan menghitung selisih antara penerimaan yang diterimah dari hasil usaha tani padi sawah dengan total biaya produksi padi sawah yang dikeluarkan. Untuk mengetahui pendapatan responden dalam usaha tani padi dapat dianalisis dengan rumus pendapatan yaitu:

$$
\begin{array}{ll}
\text { Total Penerimaan } & =\text { Rp. } 838.656 .000 \\
\text { Total Biaya } & =\text { Rp. } 165.426 .350
\end{array}
$$

Rumus

$$
\begin{aligned}
\pi & =\mathrm{TR}-\mathrm{TC} \\
& =\text { Rp. } 838.656 .000-\mathrm{Rp} .165 .426 .350 \\
\Pi & =\text { Rp.673.229.650 }
\end{aligned}
$$

Berdasarkan analisis tersebut dapat diketahui pendapatan usaha tani padi sawah yang dikeluarkan oleh 25 responden Di Kelurahan Salomallori Kecematan Dua Pitue Kabupaten Sidrap yaitu sebanyak Rp. 673.229.650 per-panen. Rata-rata pendapatan usaha tani yang dikeluarkan Rp.26.929.186. Hal ini sejalan dengan penelitian Namri (2017) dengan penelitian Di Kelurahan Watang Suppa Kecematan Suppa Kabupaten Pinrang dengan pendaptan yang dihasilkan sebesar Rp. 51.979.764.

\section{a. Uji Kelayakan R/C Ratio}

Penerimaan : Rp. 838.656.000

Total Biaya : Rp. 165.426.350

Rumus :

$$
\begin{aligned}
\mathrm{R} / \mathrm{C}= & \frac{T R}{T C} \\
= & \frac{838.656 .000}{165.426 .350}=5 \\
& \text { Nilai R/C Ratio } 5 \text { menunjukkan }
\end{aligned}
$$
bahwa usaha tani padi layak untuk di usaha tanikan karena R/C Ratio yang di dapat 5 sama dengan 1 (R/C Ratio > 1) .

Kriteria:

a. R/C Ratio > $1=$ usaha tani memperoleh keuntungan (layak)

b. $\quad$ R/C Ratio $<1=$ usaha tani mengalami kerugian (tidak layak)

c. $\quad \mathrm{R} / \mathrm{c}$ ratio $=1=$ usaha tani mengalami titik impas.

Hal ini sejalan dengan penelitian Namri (2017) dengan penelitian Di 
Kelurahan Watang Suppa Kecematan Suppa

Kabupaten Pinrang dengan R/C Ratio sebesar 2,08.

\section{b. Kesejahteraan}

Kesejahteraan diartikan sebagai kemampuan keluarga untuk memenuhi kebutuhan untuk bisa hidup layak, sehat dan produktif. Klasifikasi kesejahteraan yang digunakan terdiri dari dua klasifikasi, yaitu rumah tangga sejahtera dan belum sejahtera.

a) Kependudukan: Penduduk di Kelurahan Salomallori semakin meningkat dilihat dari banyak orang dari luar yang membagun rumah sehingga lahan pertanian juga dijadikan sebagai lahan untuk membagun rumah, pertumbuhan penduduk di Kelurahan Salomallori menyebabkan banyak persaingan antar penduduk di mana persaingan untuk kerjaan dan persaingan akan tempat tinggal dimana orang disana berlomba-lomba untuk memperbaiki rumah melihat orang yang sekitarnya memiliki tempat tinggal yang bagus.

b) Kesehatan dan Gizi: Penduduk di sana sangat memperhatikan soal kesehatan sehingga kebanyak penduduk yang mengurus BPJS-nya alasannya karena itu bisa membantunya di masa depan pada saat kesehatannya terganggu, penduduk disana mengatakan bahwa apabila kesehatannya terganggu diwaktu yang tidak tepat seperti tidak memiliki uang sehingga BPSJ itu sangat berguna baginya.

c) Pendidikan: Rata-rata pendidikan responden itu SMA dan SD sehingga penduduk disana sangat mementingkan pendidikan anak-anak. Petani disana perpendapat bahwa dengan pendidikan anak-anak yang semakin tinggi maka bisa mengubah kehidupannya. Semakin tinggal sekolah maka semakin besar potensi untuk memdapatkan kerjaan yang bagus sehingga bisa meningkatkan pendapatan keluarga.

d) Ketenaga Kerjaan: Di Kelurahan Salomallori pengangguran sudah tidak banyak lagi karena masyarkat pintar untuk cari kerja baik itu kerja sebagai petani, kuli maupun pedagang. Apalagi di daerah disana masyarakat melakukan proses usaha tani dengan memberikan kepada buruh usaha tani untuk mengerjakan suatu proses usahtani seperi pemupukan dan penanaman dengan sistem bayar upah sehingga lapangan kerja ada.

e) Taraf dan Pola Konsumsi: masyarakat disana apabila pendapatan tinggi maka mereka menggunakannya untuk membeli barang atau perabotan rumah 
seperti kursi, meja makan, lemari, dan kasur, dan mereka juga menggunakan untuk membagun rumah dan membeli alat transportasi, dan mereka juga menambahkan lahan sawahnya yang dimiliki agar pendapatannya semakin tinggi.

f) Perumahan dan Lingkungan: Di Kelurahan Salomallori perumahan masyarakat disana sudah sangat bagus lihat dari rumah-rumah yang dimiliki masyarakat dimana bagunan rumah masyarakat di sana kebayakan rumah batu dan rumah kayu yang berkaca karena dilihat dari lingkungan masyarakat disana mereka mengikuti trang sekarang yang mau mencoba untuk melakukan hal-hal yang modern seperti memggunakan hp yang sudah merek terbaru, motor dan mobil yang lebih mahal atau yang terbaru dan memakai pakainya yang sekarang trang mereka mengikuti apa yang ada disekitrnya.

g) Kemiskinan: Masyarakat disana sudah di bilakang bukan masyarakat yang tergolong miskin lihat sekarang orangorang disana sudah memiliki kendaraan pribadi, rumah-rumah yang sudah layak untuk ditempati dan sudah menggunakan alat-alat elektronik tidak seperti dulu hanya beberapa orang yang memiliki kendaraan dan alat elekrtonik di rumahnya.

h) Sosial, Budaya dan Agama: Adat istiadat mereka masih berlaku saat ini seperti setelah panen maka masyarakat disana melakukan tradisi mappadengdang tradisi ini sudah lama dilakukan di Kelurahan Salomallori dan masyarakat di sana masih melakukan yang namanya baca-baca dan menyalakan api setiap malam jum'at tapi hanya sebagian masyarakat melakukan hal tersebut. Kelurahan Salomallori gotong royong sudah mulai tidak ada lagi atau sudah hampir punah di karena pekerjaan yang biasa dilakukan dengan gotong royong di gantikan dengan pekerja yang di bayar untuk melakukan bekerjaan tersebut dengan sistem pembayaran upah. Masyarakat di sana masih percaya yang namanya tahayul dimana percaya bahwa hal tersebut bisa mendatangkan bahaya masih percaya guna-guna atau biasa disebut santek-santek kepercayaan itu sudah sejak lama dan saat ini masih percaya dengan hal tersebut. 


\section{KESIMPULAN DAN SARAN}

Berdasarkan hasil dan pembahasan penelitian yang telah diuraikan maka disimpulkan sebagai berikut:

1. Jumlah pendapatan usaha tani yang diperoleh petani di Kelurahan Salomallori sebesar yaitu Rp. 579.338 .825 .

2. Tingkat kesejahteraan petani padi sawah di Kelurahan Salomallori masih tergolong cukup rendah.

3. Usaha tani padi sawah di Kelurahan Salomallori Kecematan Dua Pitue Kabupaten Sidrap layak untuk dikembangkan.

\section{DAFTAR PUSTAKA}

Abdul Hamid. 2016. Analisis Pendapatan Petani Padi Sawah. Universitas Teuku Umar. Aceh Barat.

Arikunto, S. 2002. Metodologi Penelitian Suatu Pendekatan Proposal. Jakarta: PT. Rineka Cipta.

Asa Alfrida dan Trisna Insan Noor. 2017. Analisis Pendapatan Dan Tingkat Kesejahteraan Rumah Tangga Petani Padi Sawah Berdasarkan Luas Lahan. Universitas Padjadjaran.

Badan Pusat Statistik. 2007. Indikator Ekonomi. Badan Pusat Statistik Provinsi Lampung. Bandar Lampung.

Badan Pusat Statistik 2020. Indikator Kesejahteraan Rakyat 2020. Badan Statistik Indonesia.

Citra Kurnia Putri dan Trisna Insan Noor. 2018. Analisis Pendapatan Dan Tingkat Kesejahteraan Rumah Tangga Petani Padi Sawah Berdasarkan Luas Lahan Di Desa Sindangsari, Kecamatan Banjarsari, Kabupaten
Ciamis, Provinsi Jawa Barat. Universitas Padjadjaran, Sumedang, Jawa Barat.

Dwi Ega Prasetio. 2018. Analisis Pendapatan Dan Tingkat Kesejahteraan Petani Padi Sawah (Oryza Satifa). Universitas Lampung. Lampung

.Hastuti, DHD. dan Rahim, ABD. 2008. Pengantar, Teori, dan Kasus Ekonomik Pertanian. Penebar Swadaya. Jakarta.

Hartoyo, Lutifah, Mulyani. 2010. Kondisi Sosial Ekonomi dan Tingkat Kesejahteraan Keluarga."Kasus di Wilayah Pesisir Jawa Barat ". Jurnal Ilmu Keluarga dan Konsumsi Volume 3 No. 1-10.

Hernanto, F. 1994. Ilmu Usaha Tani. Penebar Swadaya. Jakarta.

Purnamaningsih, R. 2006. Induksi Kalus dan Optimasi Regenerasi Empat Varietas Padi melalui Kultur In Vitro.Jurnal AgroBiogen 2 (2): 74-80.

Purwono dan Purnawati. 2007. Bertanam Padi Unggul. Penebar Sawadaya. Jakarta.

Rahim, A dan Hastuti. 2008. Ekonomika Pertanian. Penebar Swadaya. Jakarta.

Rodjak, A. 2002. Manajemen Usaha tani. Pustaka Giratuna. Bandung.

Sajogyo. 1997. Garis Kemiskinan dan Kebutuhan Minimum Pangan. LPSB IPB. Bogor.

Soekartawi, 2002. Prinsip Dasar Manajemen Pemasaran Hasil-Hasil Pertanian Edisi Revisi. Penerbit Raja Grafindo Persada, Jakarta, 2003. Agribisnis, Teori dan Aplikasinya, Jakarta : PT. Gajah Grafindo Persada

Soekartawi. 2003 . Teori Ekonomi Produksi. Raja Grafindo Persada. Jakarta.

Soeratno.1996. Ekonomi Pertanian. Universitas Terbuka. Jakarta.

Suratiyah, K. 2015. Ilmu Usaha tani Edisi Revisi. Penebar Swadaya. Jakarta.

Wisma, 2012. Karakteristik Fungsi Produksi Usaha tani Pangan di Indonesia. 
Jurnal Ilmiah Edukasi Volume 2 Nomor 12 Tahun Kelima. Jakarta. 